\title{
Isolation and characterization of a Forssman antigen-binding lectin from velvet bean (Mucuna derringiana) seeds
}

\author{
HANQING MO and IRWIN J. GOLDSTEIN* \\ Department of Biological Chemistry, University of Michigan, Ann Arbor, Michigan 48109, USA \\ Received 19 April 1994
}

\begin{abstract}
A Forssman antigen (GalNAc $\alpha 1-3 \mathrm{GalNAc} \beta 1-3 \mathrm{Gal} / 1$-4Gal $\beta 1-4 \mathrm{Glc} \beta 1-1 \mathrm{Cer}$ )-binding lectin has been purified from velvet bean (Muctina derringiana) seeds by a combination of affinity chromatography and reversed phase HPLC. This lectin agglutinates both native and trypsin-treated sheep erythrocytes as well as trypsinized rabbit erythrocytes, but neither native rabbit nor human erythrocytes, irrespective of blood group type. SDS-PAGE and gel filtration chromatography reveal the lectin to be a homodimer consisting of two $54 \mathrm{kDa}$ subunits linked by non-covalent bonds. The results obtained by quantitative precipitation, haemagglutination inhibition and TLC overlay assays indicate that the Mucuna lectin specifically recognizes Forssman antigen and Forssman disaccharide (GalNAc $\alpha 1-3$ GalNAc)-related structures.

Keywords: Mucuna (Mucuna derringiana) lectin; velvet bean lectin; haemagglutinin; Forssman antigen binding lectin

Abbreviations: The abbreviations and the trivial names used are: $\mathrm{AH}, 6$-aminohexyl; BSA, bovine serum albumin; Cer, ceramide; HPLC, high performance liquid chromatography; PAGE, polyacrylamide gel electrophoresis; PBS, $10 \mathrm{~mm}$ phosphate-buffered saline, pH 7.2, containing $0.15 \mathrm{M} \mathrm{NaCl}$; PMSF, phenyl methyl sulfonyl fluoride; SDS, sodium dodecyl sulphate; TFA, trifluoroacetic acid; TBS, $20 \mathrm{~mm}$ tris-buffered saline, $\mathrm{pH} 7.2$; TLC, thin-layer chromatography; A disaccharide, GalNAc $\alpha 1-3 \mathrm{Gal}$; A trisaccharide, GalNAc $\alpha 1-3[\mathrm{Fuc} \alpha 1-2] \mathrm{Gal}$; Forssman disaccharide, GalNAc $\alpha$-3GalNAc; $\mathrm{CDH}$ (ceramide dihexoside or lactosyl ceramide) Gal $\beta 1-4 \mathrm{Glc} \beta 1-1 \mathrm{Cer}$ (LacCer); CTH (ceramide trihexoside or globotriosyl ceramide), Gal $\alpha 1-4 \mathrm{Gal} \beta 1-4 \mathrm{Glc} \beta 1-1 \mathrm{Cer}$ (GbOse ${ }_{3} \mathrm{Cer}$ or $\mathrm{Gb}_{3}$ ); globoside (globotetraosyl ceramide), GalNAc $\beta 1-3 \mathrm{Gal} 1-4 \mathrm{Gal} \beta 1-4 \mathrm{Glc} \beta 1-1 \mathrm{Cer}$ (GbOse ${ }_{4} \mathrm{Cer}$ or $\mathrm{Gb}_{4}$ ); Forssman antigen (globopentaosyl ceramide), GalNAc $\alpha 1-3 \mathrm{GalNAc} \beta 1-3 \mathrm{Gal} \alpha 1-4 \mathrm{Gal} \beta 1-4 \mathrm{Glc} \beta 1-1 \mathrm{Cer}\left(\mathrm{GbOse}_{5} \mathrm{Cer}\right)$.
\end{abstract}

\section{Introduction}

Lectins are specific carbohydrate-binding proteins (or glycoproteins) of nonimmune origin that agglutinate cells and/or precipitate glycoconjugates [1]. They are distributed ubiquitously in nature, being found in plants, fungi, viruses, bacteria, invertebrates and vertebrates [2].

In the plant kingdom, lectins are particularly abundant in the family leguminoseae [3-5], and it has been hypothesized that these lectins may play a critical role in the nitrogen-fixing symbiosis between leguminous plants and Rhizobium [4, 6-9]. Some leguminous seeds were claimed by earlier investigators to be 'non-haemagglutinating' [10-12]; nevertheless, the possibility of false negative results cannot be ruled out if, for example, the lectin co-exists with endogenous inhibitor(s) and/or endogenous ligand(s); or if the lectin receptors present in the cells used in the

* To whom correspondence should be addressed. haemagglutination assays are insufficient in number or in a cryptic state.

As a part of our recent efforts to re-examine these 'non-haemagglutinating' legume seeds, a lectin with affinity towards Forssman glycolipid (GalNAc $\alpha 1-3$ GalNAc $\beta 1$ 3 Gal $\alpha 1-4 \mathrm{Gal} \beta 1-4 \mathrm{Glc} \beta 1-1 \mathrm{Cer}$ ) and Forssman disaccharide (GalNAc $\alpha 1-3 \mathrm{GalNAc}$ ) - related structures has been isolated from velvet bean (Mucuna derringiana) seeds and its properties studied.

This paper deals with the purification of the Mucuna lectin and the characterization of its physicochemical and carbohydrate binding properties.

\section{Materials and methods}

Saccharides

Various monosaccharides and their derivatives were purchased from Sigma Chemical Co. (St Louis, MO) and 
Pfanstiehl Laboratories, Inc. (Waukegan, IL). Methyl 2-acetamido-2-deoxy- $\alpha$-D-galactopyranoside and methyl 2-acetamido-2-deoxy- $\beta$-D-galactopyranside were obtained from Calbiochem (La Jolla, CA). Phenyl 2-acetamido-2deoxy- $\alpha$-D-galactopyranoside (phenyl $\alpha$ GalNAcp), pnitrophenyl 2-acetamido-2-deoxy- $\alpha$-D-galactopyranoside (p-nitrophenyl $\alpha$ GalNAcp) and o-nitrophenyl-2-acetamido2-deoxy- $\alpha$-D-galactopyranoside (o-nitrophenyl $\alpha$ GalNAcp) were obtained from Glycoside Products Company (Evanston, IL). The disaccharides, GalNAc $\alpha 1-3 \mathrm{Gal}$ and GalNAc $\alpha 1-$ 6Gal, were prepared by N. Plessas; 6-O-p-nitrophenyl methyl $\alpha$-D-galactopyranoside was synthesized by $\mathrm{Dr} \mathrm{Y}$. Meah of this laboratory. The trivalent GalNAc glycoside $(\text { GalNAcAH })_{3}$ was a gift from Dr Y. C. Lee of Johns Hopkins University.

\section{Miscellaneous materials}

Velvet bean (Mucuna derringiana) seeds were purchased from Lawyer Nursery Inc. (Plains, MT). Synsorb-Forssman discharide (GalNAc $1-3 \mathrm{GalNAc} \beta-O-\left(\mathrm{CH}_{2}\right)_{8} \mathrm{CONH}-$ Synsorb), Forssman disaccharide hapten (GalNAcol$\left.3 \mathrm{GalNAc} \beta-O-\left(\mathrm{CH}_{2}\right)_{8} \mathrm{COOCH}_{3}\right)$, A-disaccharide (GalNAc $\alpha$ 1-3Gal)-BSA, A-trisaccharide (GalNAc $\alpha$ 1-3 [L-Fuc $\alpha 1-$ 2]Gal)-BSA and GalNAc $\alpha 1-4 \mathrm{Gal}-\mathrm{BSA}$ were obtained from Chembiomed Ltd. (Edmonton, Alberta, Canada) and Alberta Research Corp. (Edmonton, Alberta, Canada). $N$-acetyllactosamine $\quad(\mathrm{Gal} \beta 1-4 \mathrm{GlcNAc} \beta-O-\mathrm{S}-\mathrm{CONH})_{16^{-}}$ BSA and GlcNAc $\beta 1-6 \mathrm{Gal}-\mathrm{BSA}$ were the products of Sockerbolaget, Swedish Sugar Co., Ltd (Arlov, Sweden). Pre-coated plastic-backed thin layer chromatography sheets, Polygram sil $G$, were the products of MachereyNagel (Germany). Polyisobutyl methacrylate (PIBM) was from Aldrich Chemical Company, Inc. (Milwaukee, WI). Gelatin and $N$-hydroxysuccinimidobiotin were from Sigma Chemical Co. Streptavidin-alkaline phosphatase, 5-bromo4-chloro-3-indolylphosphate p-toluidine salt (BCIP) and nitroblue tetrazolium chloride (NBT) were from Gibco BRL (Gaithersburg, MD). Trypsin was obtained from Worthington Biochemical Co. (New Jersey). Sephacryl S-200 HR was a product of Pharmacia Fine Chemicals (Uppsala, Sweden). Standard neutral glycolipids, i.e. lactosyl ceramide, globotriosyl ceramide and globotetraosyl ceramide were kindly provided by Dr S. Basu of Notre Dame University. Authentic Forssman glycolipid (globopentaosyl ceramide) was a generous gift of Dr S-I. Hakomori of the Biomembrane Institute, Seattle. Fetuin, transferrin, thyroglobulin, bovine submaxillary mucin were obtained from Sigma Chemical Co. Ovine submaxillary mucin was a gift of Dr A. E. Eckhardt of Duke University; glycophorin was prepared by Dr S. J. Rinderle of this laboratory; $x_{1}$-acid glycoprotein was a gift of Dr G. W. Jourdian, University of Michigan. Asialoglycoproteins and asialomucins were prepared by heating the corresponding parental glycoproteins in $0.1 \mathrm{M}$ hydrochloric acid at $80^{\circ} \mathrm{C}$ for $1 \mathrm{~h}$, followed by dialysis against distilled water and lyophilization. The

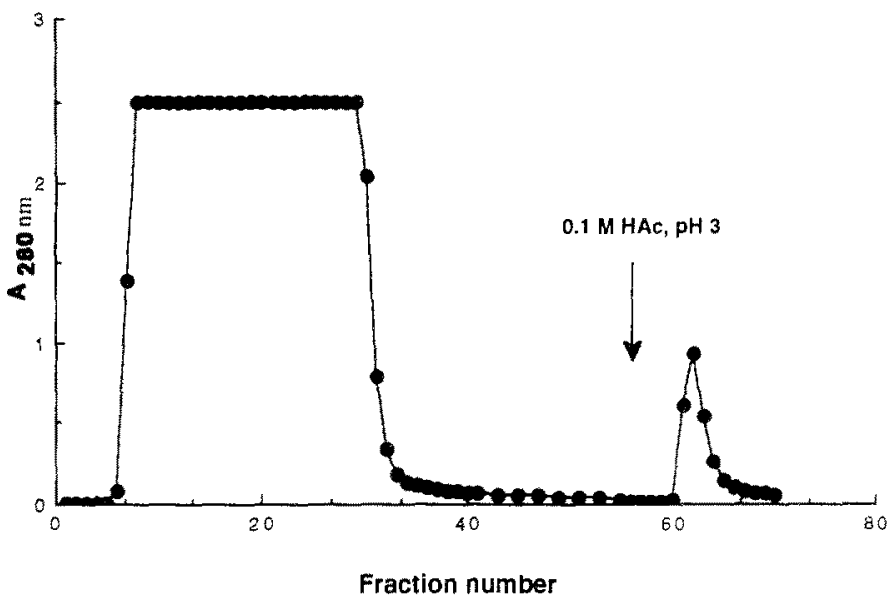

Figure 1. Isolation of the Mucuna lectin on a Forssman disaccharide-Synsorb column. Mucuna crude extract ( $400 \mathrm{mg}$ ) obtained from $60-80 \%$ ammonium sulphate fractionation was applied onto a Forssman disaccharide-Synsorb column $(1.4 \times 15 \mathrm{~cm}$, bed volume $23 \mathrm{ml}$ ). The haemagglutinin was desorbed, at the arrow, with $0.1 \mathrm{M} \mathrm{HAc}$, pH 3.0. Fractions of 80 drops per tube (approx. $2.5 \mathrm{ml}$ per tube) were collected and monitored by absorbance at $280 \mathrm{~nm}$.

removal of sialic acid from the glycoproteins was ascertained by the thiobarbituric acid assay [13-14]. Various blood type human erythrocytes and human sera were obtained from the Blood Bank, University of Michigan Hospital. Rabbit and sheep erythrocytes were obtained from mature and healthy animals; the trypsinized erythrocytes were prepared as described by Lis and Sharon [15].

\section{Isolation of mucuna lectin}

All procedures were carried out at $4^{\circ} \mathrm{C}$. After peeling off the testa, the velvet bean (Mucuna derringiana) seeds were finely ground using a Cyclone Sample Mill (UD Corporation, Boulder, $\mathrm{CO}$ ), defatted with methanol and dichloromethane, and air-dried at room temperature. The flour was extracted three times with 5 volumes (V/W) of PBS containing $1 \mathrm{~mm}$ PMSF (phenylmethylsulfonyl fluoride) and the extract was centrifuged $(10000 \times \mathrm{g}, 30 \mathrm{~min})$. The clear supernatant solutions were combined and subjected to ammonium sulphate fractionation. The precipitate formed between 60 and $80 \%$ ammonium sulphate saturation was collected and dialysed against PBS. After clarifying by centrifugation, the dialysate was applied onto a SynsorbForssman disaccharide (GalNAc $\alpha 1-3 \mathrm{GalNAc} \beta-O-\left(\mathrm{CH}_{2}\right)_{8-}$ CONH-Synsorb) column $(1.4 \times 15 \mathrm{~cm}$, bed volume $23 \mathrm{ml})$ pre-equilibrated with $\mathrm{PBS}$ and the eluate was monitored by absorbance at $280 \mathrm{~nm}$. After washing the column with PBS, the affinity-adsorbed lectin was desorbed with $0.1 \mathrm{M}$ acetic acid, pH 3.0 (Fig. 1), collected, dialysed immediately against distilled water and lyophilized.

The final purification was achieved by reversed phase HPLC on a C-4 column $(1 \times 25 \mathrm{~cm})$ using a linear gradient 
from $100 \%$ A $(0.1 \%$ TFA) to $100 \%$ B $(0.08 \%$ TFA, $75 \%$ acetonitrile) in $60 \mathrm{~min}$.

\section{Haemagglutination and inhibition assays}

The haemagglutinating activity of the lectin and the inhibitory potency of various carbohydrates were determined by a two-fold serial dilution procedure as described previously [16] using various fresh and trypsin-treated erythrocytes.

Polyacrylamide gel electrophoresis (PAGE) and sodium dodecyl sulphate-polyacrylamide gel electrophoresis (SDS-PAGE)

Native gel electrophoresis was carried out in Tris/glycine buffer, $\mathrm{pH} 8.9$, using a $10 \%$ polyacrylamide gel according to the method of Davis [17]. Polyacrylamide gel electrophoresis in the presence of sodium dodecyl sulphate was performed using a $12 \%$ gel according to the method of Laemmli [18]. Protein bands were visualized by Coomassie Brilliant Blue R-250 staining. The proteins used as molecular mass markers were rabbit muscle phosphorylase $b$ $(97.4 \mathrm{kDa})$, BSA $(67 \mathrm{kDa})$, hen egg white ovalbumin $(45 \mathrm{kDa})$, bovine carbonic anhydrase $(31 \mathrm{kDa})$, soybean trypsin inhibitor $(21.5 \mathrm{kDa})$ and hen egg white lysozyme $(14.4 \mathrm{kDa})$.

\section{Protein estimation}

Protein concentration was determined by the method of Lowry et al. [19], using bovine serum albumin as standard.

\section{Molecular mass estimation}

The molecular mass of the purified Mucuna lectin was estimated by SDS-PAGE and by gel filtration chromatography was carried out on a Sephacryl S-200 HR column $(0.9 \times 104 \mathrm{~cm}$; bed volume, $68 \mathrm{ml})$ operating at room

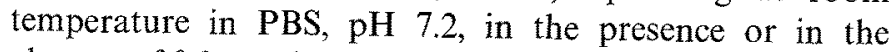
absence of $0.2 \mathrm{M}$ galactose. The column was calibrated with the following standard proteins: bovine serum albumin $(67 \mathrm{kDa})$, ovalbumin $(45 \mathrm{kDa})$, carbonic anhydrase ( $29 \mathrm{kDa})$, chymotrypsinogen A ( $25 \mathrm{kDa})$, and cytochrome $\mathrm{C}(12.5 \mathrm{kDa})$.

\section{Amino acid composition analysis}

The purified Mucuna lectin sample was hydrolysed for $24 \mathrm{~h}$ at $110^{\circ} \mathrm{C}$ in $6 \mathrm{M} \mathrm{HCl}$ and the amino acid composition analysed using an Applied Biosystems model $420 \mathrm{~A}$ amino acid analyser.

\section{Amino acid sequencing}

$\mathrm{N}$-terminal amino acid sequencing was conducted using an Applied Biosystems (Foster City, CA) model 470 A protein sequencer interfaced with an Applied Biosystems model 120 A on-line analyser. The cyanogen bromide cleavage was conducted using $2 \mu \mathrm{g} \mathrm{CNBr}$ per $\mu \mathrm{g}$ of protein in $70 \%$ formic acid at room temperature overnight in the dark [20]; lysylendopeptidase digestion was carried out as described by Stone et al. [21]. The fragments obtained from lysylendopeptidase digestion and cyanogen bromide cleavage were separated by HPLC and SDS-PAGE followed by electroblotting onto a polyvinylidene difluoride membrane (Applied Biosystems, Inc.), and sequenced using an Applied Biosystems model 473 protein sequenator according to the manufacturer's instruction.

\section{Quantitative precipitation assays}

Quantitative precipitation assays were performed by a microprecipitation technique described by So and Goldstein [22].

\section{Preparation of biotin-mucuna lectin conjugate}

Biotinylation of Mucuna lectin was performed as described by Bayer et al. [23], but in the presence of $0.1 \mathrm{M} \mathrm{N}$ acetylgalactosamine to protect the carbohydrate combining site. After coupling, the lectin activity was reassayed by haemagglutination assay.

\section{Thin-layer chromatography (TLC) and TLC immunostaining}

Thin layer chromatography and immunostaining were conducted on pre-coated, plastic-backed silica gel, Polygram Sil G, sheets, as described by Smith [24] and Brockhaus et al. [25] with slight modifications as follows: prior to chromatography, the TLC sheet was pre-developed with chloroform:methanol 2:1 (v/v) and allowed to dry. Neutral glycolipids were separated using chloroform:methanol:water 65:25:4 (by volume) as the developing solvent. After chromatography, the dried chromatogram was immersed for $1 \mathrm{~min}$ in a solution of $0.1 \%(\mathrm{w} / \mathrm{v})$ polyisobutylmethacrylate in hexane. The sheet was then blocked by dipping in PBS, pH 7.2, containing $1 \%$ gelatin and $0.1 \%$ $\mathrm{NaN}_{3}$ at room temperature overnight. After draining off the excess blocking solution, the TLC sheet was overlayered with biotinylated lectin diluted to $50 \mu \mathrm{g} \mathrm{ml}^{-1}$ with Trisbuffered saline (TBS), pH 7.2, containing 1\% BSA and incubated at room temperature in a petri dish under a humidified atmosphere for $24 \mathrm{~h}$. After removing the biotinlectin conjugate solution, the TLC sheet was washed five times with PBS containing 0.05\% Tween 20,2 min for each wash, and overlayered with streptavidin-alkaline phosphatase (1:1000 diluted with TBS containing 1\% BSA) for $4 \mathrm{~h}$ at room temperature. After six washings in TBS, the lectin binding glycolipids were visualized with 5-bromo-4chloro-3-indolylphosphate p-toluidine salt (BCIP) and nitroblue tetrazolium chloride (NBT). A replicate chromatogram was sprayed with orcinol reagent for visualizing the total neutral glycolipids.

\section{Results}

Haemagglutinating activity

The crude extract of Mucuna derrigiana seeds agglutinated fresh and trypsin-treated sheep erythrocytes as well as 


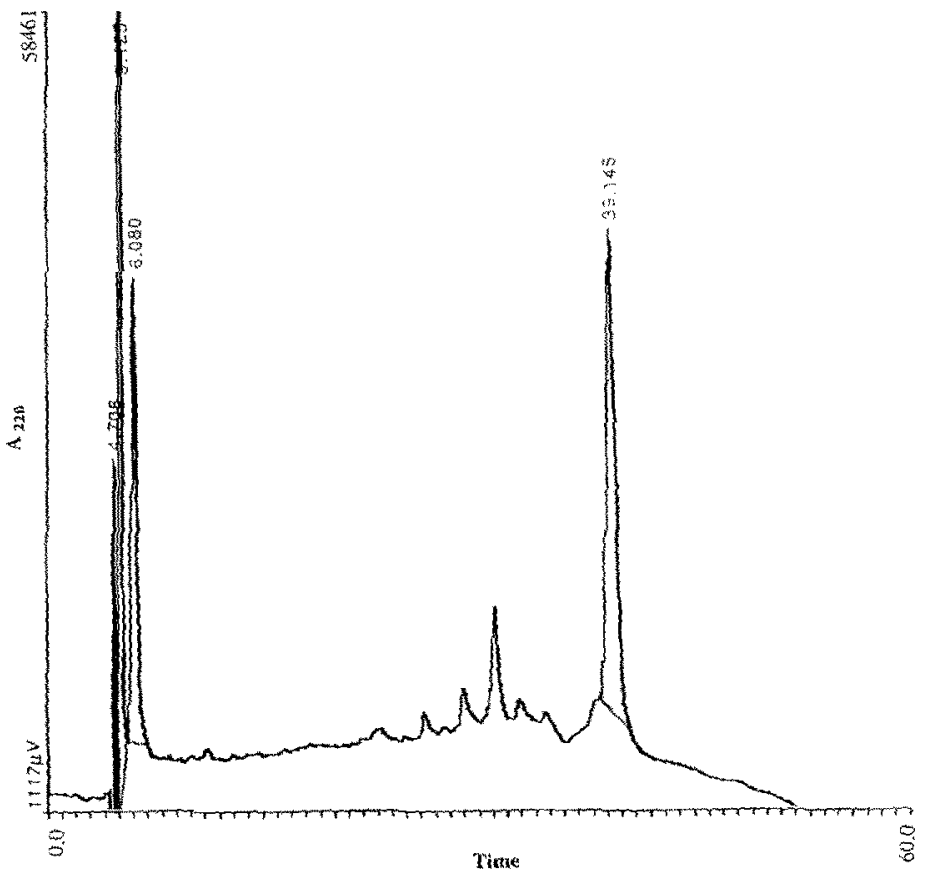

Figure 2. Purtication of the Mucuna lectin by reversed phase HPLC on a C-4 column. The crude Mucuna lectin obtained from affinity chromatography on a Forssman-disaccharideSynsorb column was applied onto a reversed phase HPLC C. 4 column $(1 \times 25 \mathrm{~cm})$. The separation was achieved using a limear gradient from $100 \%$ A $(0.1 \%$ TFA) to $100 \% \mathrm{~B}(0.08 \%$ TFA, $75 \%$ acetonitrile) in 60 min. The major protein peak was the purified Mucuna lectin.

trypsin-treated rabbits erythrocytes, but failed to agglutinate fresh rabbit, and both fresh trypsin-treated human red blood cells, irrespective of the ABO blood group type. The haemagglutinating activity did not require bivalent cations.

The minimum concentration of the purified Mucuna lectin required for agglutinating trypsin-treated erythrocytes was $0.3 \mu \mathrm{g} \mathrm{ml}^{-1}$.

\section{Isolation of Mucuna lectin}

Although the carbohydrate binding specificity of the crude extract of Mucuna seeds was found to be toward galactose and $N$-acetyl-D-galactosamine, the lectin activity was not retained by galactose-based affinity matrices including: Sepharose, acid-treated Sepharose, divinylsulfone-activated, galactose or lactose derivatized Sepharose and an asialofetuin-Sepharose column. The lectin activity was finally found to be adsorbed by a synthetic affinity matrix having nonreducing terminal GalNAc $x$-3GalNAc disaccharide units linked to crystalline silica beads, i.e. Forssman disaccharide (GalNAcx1-3GalNAc)-Synsorb. The result of affinity chromatography of the crude Muctua extract on a Forssman disaccharide-Synsorb column is shown in Fig. 1. The haemagglutinating activity was eluted with $0.1 \mathrm{M}$ acetic acid, and both reversed phase HPLC and polyacrylamide gel electrophoresis revealed that this fraction contained one

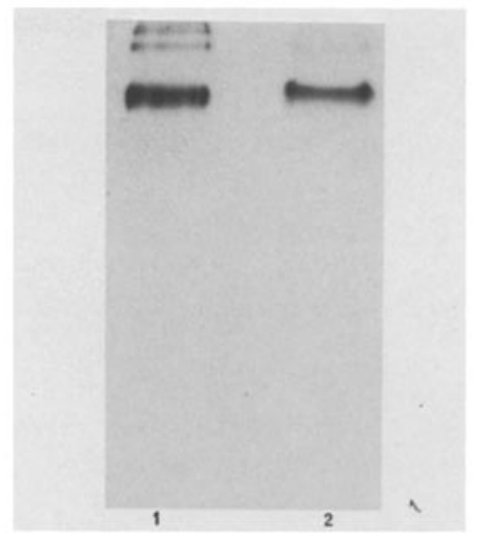

Figure 3. Native polyacryiamide gel electrophoretic pattern of the Mucuna lectin. From left to right: Lane 1: Crude Mucuna lectin isolated from affinity chromatography on a Forssmandisaccharide-Synsorb column contains one major protein band and several slow moving minor bands. Lane 2: HPLC-purified Mucuna lectin.

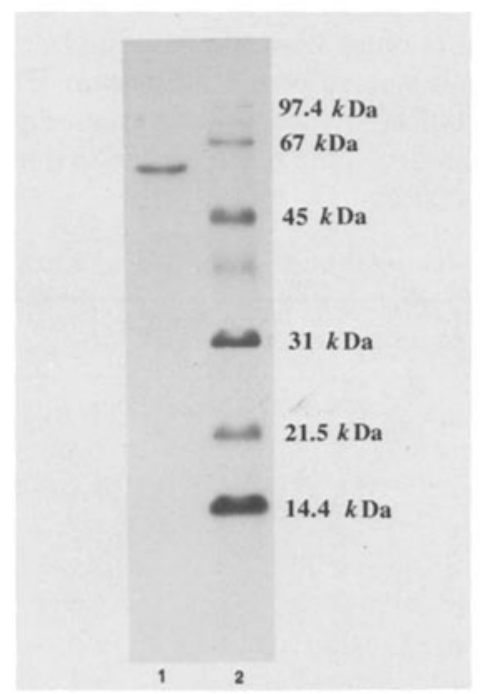

Figure 4. SDS-PAGE of the HPLC-purified Muctua lectin. From left to tight: Lane 1: HPLC-purified Mucuna lectin (treated with $\beta$-mercaptoethanol). Lane 2: Molecular mass standards. From top to bottom: phosphorylase $\mathrm{b}(97.4 \mathrm{kDa})$; bovine serum albumin (67 kDa); ovalbumin ( $45 \mathrm{kDa})$; carbonic anlydrase (31 kDa); soybean trypsin inhibitor $(21.5 \mathrm{kDa})$; lysozyme $(14.4 \mathrm{kDa})$.

major protein and several minor components (Figs 2 and 3); the major protein peak from HPLC was collected and used as the purified Mucuna lectin for physicochemical characterization.

\section{Molecular mass and molecular structure}

On SDS-PAGE, both in the presence and in the absence of $\beta$-mercaptoethanol, the HPLC-purified Mucuna lectin gave a single band with an apparent molecular mass of $54 \mathrm{kDa}$ (Fig. 4); under reducing conditions this protein band migrated slightly slower than it did under nonreducing 


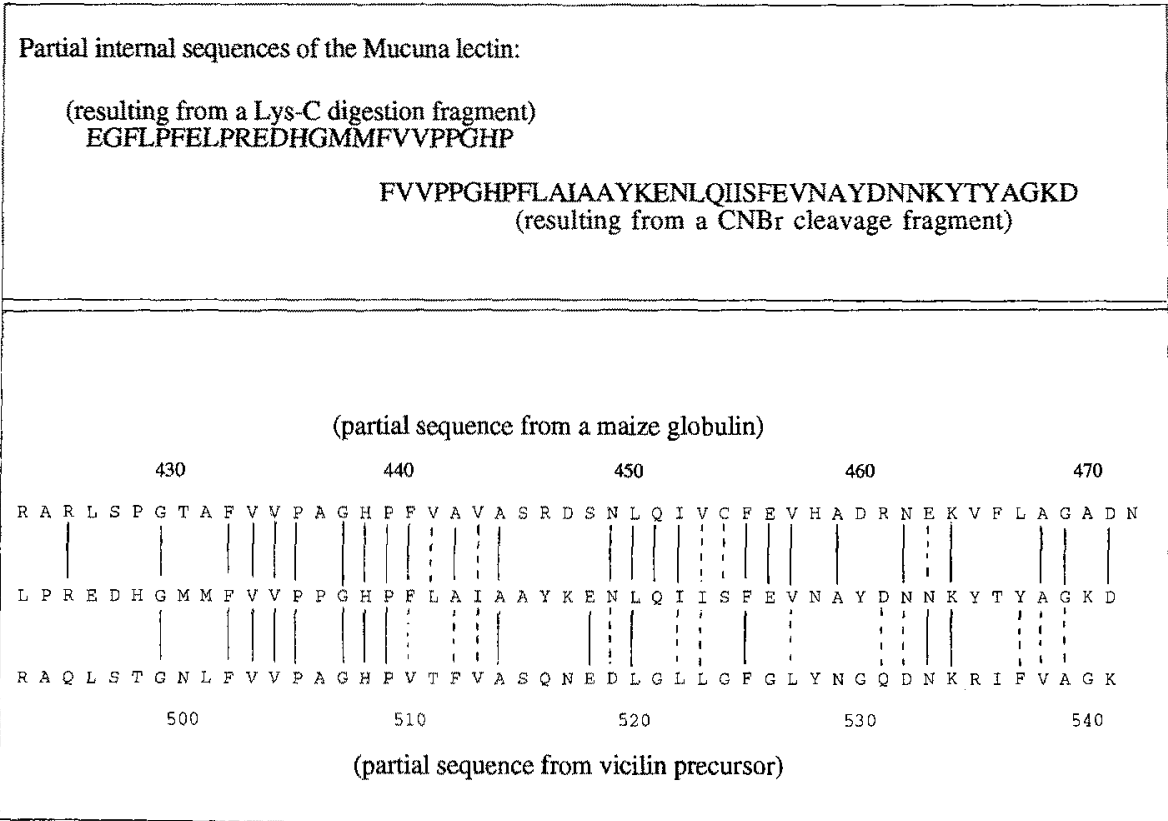

Figure 5. Partial internal sequence resulting from $\mathrm{CNBr}$ cleavage (Top) and endopeptidase Lys-C digestion and its comparison with those of two plant storage proteins (Bottom). The solid lines show identical amino acids and the dashed lines indicate homologous amino acids. The first row shows the partial sequence from a maize globulin; the middle row, the partial sequence from the $M$ ucuna lectin; and the third row, the one from the vicilin precursor.

Table 1. Amino acid composition of Mucuna lectin.

\begin{tabular}{ll}
\hline Amino acid & Mol\% \\
\hline Asx & 11 \\
Glx & 10.5 \\
Lys & 8.7 \\
Gly & 8.3 \\
Leu & 8.2 \\
Ser & 7.5 \\
Pro & 6.5 \\
Ala & 6.1 \\
Val & 5.3 \\
Phe & 5.3 \\
Arg & 5.2 \\
Thr & 4.8 \\
Ile & 4.7 \\
Tyr & 3.1 \\
His & 2.7 \\
Met & 1.6 \\
Cys & 0.4 \\
Trp & ND \\
\hline
\end{tabular}

ND, not determined.

conditions (data not shown), indicating the probable presence of intrasubunit, and the absence of intersubunit, disulfide bond(s). Gel filtration chromatography on a Sephacryl S-200 HR column conducted in PBS, pH 7.2, both in the presence or in the absence of $0.2 \mathrm{M}$ galactose, gave a single symmetric peak at an elution volume corresponding to an apparent molecular mass of $90 \mathrm{kDa}$. Taken together, these data suggest that at neutral $\mathrm{pH}$, the Mucuna lectin exists as a homodimer joined by noncovalent bond(s).

The amino acid composition of the HPLC purified Mucuna lectin is shown in Table 1. The lectin contains high concentrations of Asx, Glx, hydrophobic amino acids, and relatively high amounts of lysine and glycine. Attempts to sequence the Mucuna lectin's N-terminal amino acids failed due to a blocked amino terminus which was inert to the Edman degradation; however, an internal 56 amino acids sequence was determined by two overlapping peptides resulting from $\mathrm{CNBr}$ degradation and endopeptidase Lys-C digestion (Fig. 5).

\section{Carbohydrate binding specificity}

As will be elaborated in the Discussion, the Mucuna lectin failed to form a precipitate with any of a very large number of natural and synthetic glycoconjugates; this obviated the possibility of conducting sugar hapten inhibition of precipitation. Therefore the carbohydrate binding specificity of the Mucuna lectin was investigated by haemagglutination inhibition assay. The results are tabulated in Table 2. Of the monosaccharides tested, only D-galactose and $\mathrm{N}$-acetyl-Dgalactosamine were good inhibitors, whereas epimers of D-galactose, i.e. D-talose (the C-2 epimer) D-gulose (the C-3 epimer), and D-glucose (C-4 epimer) were all noninhibitory up to $200 \mathrm{~mm}$. $N$-Acetyl-D-galactosamine was eight times more potent than D-galactose as an inhibitor. The methyl 
Table 2. The minimum concentrations of saccharides required for complete inhibition of four haemagglutinating units of Mucuna lectin.

\begin{tabular}{|c|c|c|}
\hline Saccharide & Concentration required (mM) & Relative potency \\
\hline Galactose & 1.04 & 1 \\
\hline Methyl $\alpha$-D-Galactopyranoside & 0.52 & 2 \\
\hline Methyl $\beta$-D-Galactopyranoside & 2.08 & 0.5 \\
\hline GalNAc & 0.13 & 8 \\
\hline Methyl $\alpha$-D-GalNAcp & 0.065 & 16 \\
\hline Methyl $\beta$-D-GalNAcp & 0.52 & 2 \\
\hline Phenyl $\alpha$-D-GalNAcp & 0.033 & 32 \\
\hline o-Nitrophenyl $\alpha$-D-GalNAc $p$ & 0.065 & 16 \\
\hline$p$-Nitrophenyl $\alpha$-D-GalNAcp & 0.033 & 32 \\
\hline GalNAc $1-3 \mathrm{Gal}$ & 0.065 & 16 \\
\hline GalNAc $\alpha 1-6 \mathrm{Gal}$ & 0.13 & 8 \\
\hline Melibiose & 0.26 & 4 \\
\hline Lactose & 33.3 & 0.03 \\
\hline LacNAc & No inhibition at $50 \mathrm{~mm}$ & \\
\hline L-Arabinose & 33.3 & 0.03 \\
\hline D-Fucose & 16.7 & 0.062 \\
\hline $\begin{array}{l}\text { Forssman disaccharide-hapten } \\
\text { (GaNAc } 1 \text {-3GalNAc } \beta-O-\left(\mathrm{CH}_{2}\right)\end{array}$ & 0.035 & 30 \\
\hline
\end{tabular}

${ }^{2}$ The values were the mean of three independent experiments.

There was no inhibition by $\mathrm{L}$-fucose, D-arabinose, D-glucose, $N$-acetyl-D-glucosamine, D-gulose, D-mannose, $\mathrm{N}$-acetyl-D-mannosamine, methyl D-mannoside, D-talose, $\mathrm{L}$ - and D-xylose, $\mathrm{L}-$ and $\mathrm{D}$-rhamnose, ribose and 2 -deoxy-ribose, up to $200 \mathrm{~mm}$.

Table 3. Structures of neutral glycolipids used to characterize the carbohydrate binding specificity of the Mucuna lectin.

\begin{tabular}{|c|c|}
\hline Glycolipid & Sinucture \\
\hline Lactosyl ceramide & Gal $\beta 1-4 G \operatorname{Gl} \beta 1-1 \mathrm{Cer}$ \\
\hline Globotriosyl ceramide $\left(\mathrm{GbOse}_{3}\right)$ & Gal $\alpha 1-4 \mathrm{Gal} \beta 1-4 \mathrm{Glc} \beta 1-1 \mathrm{Cer}$ \\
\hline Globotetraosyl ceramide (GbOse ${ }_{4}$ ) (Globoside) & GalNAc $\beta 1-3 \mathrm{Gal} \alpha 1-4 \mathrm{Gal} \beta 1-4 \mathrm{Glc} \beta 1-1 \mathrm{Cer}$ \\
\hline Globopentaosyl ceramide (GbOse ${ }_{5}$ (Forssman glycolipid) & GalNAca1-3GalNAc $\beta 1-3 \mathrm{Gal} \alpha 1-4 \mathrm{Gal} \beta 1-4 \mathrm{Glc} \beta 1-1 \mathrm{Cer}$ \\
\hline
\end{tabular}

$\alpha-$ glycosides were better, whereas the corresponding $\beta$ glycosides were poorer inhibitors than the parental sugars. Of the disaccharides examined, both lactose and $N$ acetyllactosamine were inferior inhibitors compared to galactose, whereas melibiose was four-fold better an inhibitor than galactose, signifying that the lectin has a strong preference for the $\alpha$-anomeric configuration. Among the disaccharides containing nonreducing terminal $\mathrm{N}$ acetyl-D-galactosaminyl residue, the Forssman disaccharide hapten (GalNAc $\alpha 1-3 \mathrm{GalNAc} \beta-O-\left(\mathrm{CH}_{2}\right)_{8} \mathrm{COOCH}_{3}$ ) was by far the best inhibitor, being 30 -fold more potent than galactose, and four times better than $N$-acetyl-D-galactosamine. GaINAc $1-3 \mathrm{Gal}$ was two times more active than GalNAc as an inhibitor, whereas the disaccharide GalNAcal-6Gal showed an inhibitory potency similar to that of the monosaccharide GalNAc.

The carbohydrate binding specificity of the Mucuna lectin was also studied with four neutral glycolipids (Table 3) containing either a nonreducing terminal D-Gal or D-GalNAc group using a TLC overlay technique. The results are shown in Fig. 6. Mucuna lectin specifically bound Forssman glycolipid (globopentaosylceramide, GalNAc $\alpha 1-3 \mathrm{GalNAc} \beta 1-3 \mathrm{Gal} \alpha 1-4 \mathrm{Gal} \beta 1-4 \mathrm{Glc} \beta 1-$ $1 \mathrm{Cer}$ ), whereas binding to lactosylceramide, globotriosylceramide (globoside) was not observed under the conditions of this assay.

\section{Discussion}

The crude extract of Mucuna derringiana seeds agglutinates trypsin-treated, but not native, rabbit erythrocytes, implying that the lectin 'receptors' on the native rabbit red blood cell surface are in a cryptic state, possibly glycolipids in nature. This was later confirmed by TLC immunostaining experiments.

Although $\mathrm{N}$-terminal amino acid sequencing of the Mucuna lectin failed due to the blocked amino terminus, some partial internal sequences were obtained from $\mathrm{CNBr}$ 


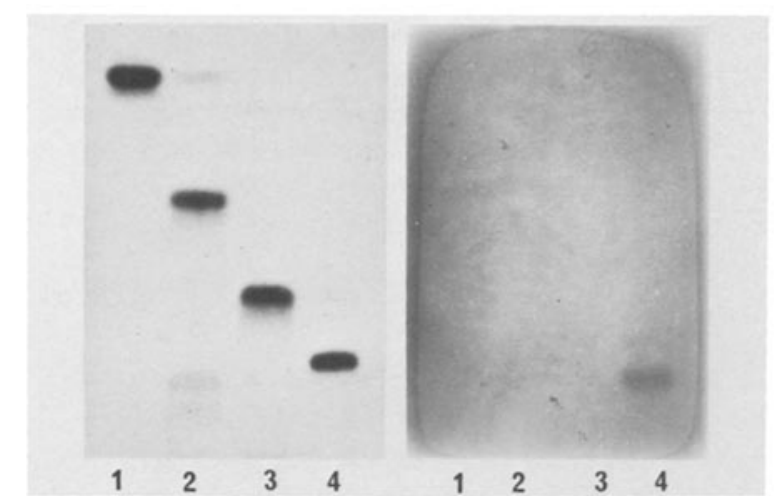

Figure 6. Thin-layer chromatogram of nentral glycolopids (Table 3). From left to right: Lane 1: LacCer. Lane 2: $\mathrm{Gb}_{3}$ (globotriosylceramide). Lane 3: $\mathrm{Gb}_{4}$ (globoside). Lane 4: Forssman glycolipid (globopentaosylceramide). Left panel; Visualized by spraying with orcinol reagent. Right panel: A replicate chromatogram stained with biotinylated-Mucuna lectin. The purified Mucuna lectin bound to Forssman glycolipid, but not to lactosylceramide, globotriosylceramide or globotetraosylceramide.

cleavage and lysylendopeptidase digestion (Fig. 5). It was interesting to note that this internal peptide sequence had considerable homology with the sequences of two plant storage proteins: vicilin precursor (34.1\% identity in 41 amino acids overlap) and maize globulin $(52.1 \%$ identity in 48 amino acids overlap (Fig. 5), because it has been well documented that in mature seeds, plant lectins are localized in the protein bodies of cotyledons, the major storage organelle [4]. Homology with other legume lectins was not observed.

Many native glycoproteins, mucins and their desialylated derivatives were tested for their ability to precipitate the Mucuna lectin, but none succeeded; among those examined were: both native and disialylated fetuin, thyroglobulin, glycophorun, $\alpha_{1}$-acid glycoprotein, transferrin, ovine submaxillary mucin, bovine submaxillary mucin, porcine blood group type A substance, defucosylated A substance and various blood type human sera. The following neoglycoproteins and glycosyl derivatives also failed to precipitate the lectin: A-disaccharide (GalNAca1-3Gal)-BSA, A-trisaccharide (GalNAc $\alpha 1-3[\mathrm{Fuc} \alpha 1-2] \mathrm{Gal}$ )-BSA, LacNAc(Gal $\beta 1$ 4GlcNAc)-BSA, GalNAc $\propto 1-4 \mathrm{Gal}-\mathrm{BSA}$, Gal $\alpha 1-4 \mathrm{Gal} \beta 1-$ 4GlcNAc-BSA and a trivalent GalNAc glycoside $(\mathrm{GalNAcAH})_{3}$.

The carbohydrate binding specificity of the Mucuna lectin was investigated by haemagglutination inhibition. Of the monosaccharides examined, only D-galactose and $\mathrm{N}$ acetyl-D-galactosamine were good inhibitors, whereas epimers of D-galactose were all noninhibitory up to $200 \mathrm{~mm}$. This result indicates that each of the hydroxyl groups of galactose may be involved, though to a different degree, in lectin binding; the $\mathrm{C}-3$ equatorial and the $\mathrm{C}-4$ axial hydroxyl groups of the D-pyranose ring are the most important loci for lectin binding. The fact that $N$-acetyl-D- galactosamine is 8 times more effective than D-galactose as an inhibitor and D-fucose is a much weaker inhibitor than D-galactose (Table 2) suggests that an equatorial acetamido group at the $\mathrm{C}-2$ position and a free hydroxyl group at the C-6 position of the pyranose ring significantly enhance its binding to the Mucuna lectin.

Both methyl $\alpha$-D-galactoside and the $\alpha$-anomer of methyl $N$-acetyl-D-galactosaminide were four to eight times more potent as an inhibitor than the corresponding $\beta$-glycosides, indicating a distinct preference of the lectin for an $\alpha$ anomeric configuration of the glycoside bond over the $\beta$-configuration. This conclusion was further confirmed by the observation that both lactose and $N$-acetyllactosamine were very poor inhibitors whereas melibiose (Gala1-6Glc) was a reasonably good inhibitor.

It was of great interest to note that the introduction of a hydrophobic aglycon such as a phenyl or nitrophenyl group significantly enhanced the affinity of the sugar for lectin binding; in fact, both phenyl 2-acetamido-2-deoxy- $\alpha$ D-galactopyranoside and p-nitrophenyl 2-acetamido-2deoxy- $\alpha$-D-galactopyranoside showed the same inhibitory potency as the Forssman disaccharide hapten. This finding suggests the presence of a nonpolar region of the lectin adjacent to the carbohydrate binding site similar to the one reported may years ago for concanavalin A [26].

Inasmuch as GalNac occurs more frequently in glycosphingolipids (especially in globo and ganglio series), four glycolipids from the globo series were chosen to explore the binding specificity of the Mucuna lectin. The results are presented in Fig. 6. Among the four glycosphingolipids tested, only globopentaosylcermide, i.e. Forssman glycolipid, bound to Mucuna lectin.

The fact that the Mucuna lectin was isolated on a Forssman-disaccharide-Synsorb column, that the Forssman disaccharide was the best inhibitor of the haemagglutination induced by the Mucuna lectin, and that the biotinylatedMucuna lectin specfically bound to Forssman glycolipid on TLC prompts us to suggest that the Mucuna lectin is specific for the Forssman disaccharide (GalNAca13GalNAc) and Forssman antigen (GalNAc 1 1-3GalNAc $\beta 1-$ $3 \mathrm{Gal} \alpha 1-4 \mathrm{Gal} \beta 1-4 \mathrm{Glc} \beta 1-1 \mathrm{Cer}$ )-related structures. This might also account for the failure of the lectin to precipitate all the glycoproteins and neoglycoproteins aforementioned, inasmuch as to the best of the authors' knowledge, none of these glycoproteins contains Forssman disaccharide-related structures.

Several haemagglutinins including Dolichos biflorus agglutinin, Helix pomatia agglutinin and Wistaria floribunda agglutinin have been reported to be reactive with the Forssman antigen [27]. However, all these lectins also agglutinate human type $\mathrm{A}$ erythrocytes and cross-react with blood group A substances [27], whereas the Mucuna lectin does not agglutinate either natural or trypsin-treated human red blood cells, irrespective of the blood group type, and fails to precipitate both native and defucosylated blood 
group A substance. This property distinguishes the Mucuna lectin from other Forssman-reactive lectins.

Humans are generally considered to be Forssman antigen negative species; however, Forssman and Forssman-like glycolipids have been detected and isolated from various human cancer tissues and carcinoma cell lines [28-32]. The unique ability of Mucuna lectin to recognize the Forssman and Forssman-like glycolipids makes it a potentially important diagnostic and therapeutic tool.

\section{Acknowledgements}

This investigation was supported by the National Institutes of Health Grant GM 29470 (to I.J.G.). We thank Charles Mitchell (University of Michigan) for amino acid sequencing, Sherry Lynn Williams (University of Michigan) for amino acid composition analysis.

\section{References}

1. Goldstein IJ, Hughes RC, Monsigny M, Osawa T, Sharon N (1980) Nature 285:66.

2. Liener IE, Sharon N, Goldstein IJ (eds) (1986) The Lectins: Properties, Functions and Applications in Biology and Medicine, Orlando: Academic Press.

3. Sharon N, Lis H (1990) FASEB J, 4:3198-208.

4. Etzler ME (1986) In The Lectins: Properties, Functions and Applications in Biology and Medicine (Liener IE, Sharon N, Goldstein IJ, eds) pp. 371-435. Orlando: Academic Press.

5. Rudiger H (1988) In Advances in Lectin Research (Franz H, ed.) Vol 1, pp. 26-72. Berlin: Springer.

6. Krupe M (1950) Z Immunitaetsforsch Exp Ther 107:450-64.

7. Hamblin J, Kent SP (1973) Nature (London) New Biol 245:28-30.

8. Bohlool BB, Schmidt EL (1974) Science 185:269-71.

9. Dazzo FB, Yanke YE, Brill WJ (1978) Biochim Biophys Acta 539:276-86.

10. Makela O (1957) Ann Med Exp Biol Fenn 35, Suppl 11:1-133.
11. Boyd WC, Waszczenko-Zacharczenko E, Goldwasser SM (1961) Transfusion 1:374-82.

12. Toms GC, Western A (1971) In Chemotaxonomy of the Leguminosae (Harborne JB, Boulter D, Turner BI, eds) pp. 367-462. New York: Academic Press.

13. Hammond KS, Papermaster DS (1976) Anal Biochem 74:292-7.

14. Warren L (1959) J Biol Chem 234:1971-5.

15. Lis H, Sharon N (1972) Methods Enzymol 28:360-8.

16. Crowley JF, Goldstein IJ (1982) Methods Enzymol 83:368-73.

17. Davis BJ (1964) Ann NY Acad Sci 121:404-27.

18. Laemmli UK (1970) Nature 227:680-5.

19. Lowry OH, Rosebrough NJ, Farr AL, Randall RJ (1951) $J$ Biol Chem 193:265-75.

20. Charbonneau H (1989) In A Practical Guide to Protein and Peptide Purification for Micro-sequencing (Matsudaira PT, ed.) pp. 15-30. San Diego: Academic Press.

21. Stone KL, LoPresti MB, Crawford JM, DeAngelis R, Williams KR (1989) In A Practical Guide to Protein and Peptide Purification for Microsequencing (Matsudaira PT, ed.) pp. 31-47. San Diego: Academic Press.

22. So LL, Goldstein IJ (1967) J Biol Chem 242:1617-22.

23. Bayer EA, Skutelsky E, Wilchek M (1979) Methods Enzymol $62: 308-15$.

24. Smith DF (1983) Biochem Biophys Res Commun 115:360-7.

25. Brockhaus M, Magnani JL, Blaszczyk M, Steplewski Z, Koprowski H, Karlsson K-A, Larson G, Ginsburg V (1981) $J$ Biol Chem 256:13223-5.

26. Poretz RD, Goldstein IJ (1968) Arch Biochem Biophys 125:1034-5.

27. Baker DA, Sugii S, Kabat EA, Ratcliffe RM, Hermentin P, Lemieux RU (1983) Biochemistry 22:2741-50.

28. Kano K, Milgrom F (1977) Curr Top Microbiol Immunol 77:635-48.

29. Mori T, Fujii G, Kawamura A Jr, Yasuda T, Naito Y, Tsumita T (1982) Immunol Commun 11:217-25.

30. Mori E, Mori T, Sanai Y, Nagai Y (1982) Biochem Biophys Res Common 108:926-32.

31. Uemura K. Hattori H, Ono K, Ogata H, Taketomi T (1989) Jpn J Exp Med 59:3239-49. 